\title{
Contra gp*- Continuous Functions
}

\author{
S. Sekar, P.Jayakumar \\ Department of Mathematics Government Arts College (Autonomous) Salem- 636 007.India \\ Department of Mathematics Paavai Engineering College, Namakkal-637018.India
}

\begin{abstract}
In this paper, the authors introduce a new class of functions called contra gp*-continuous function in topological spaces. Some characterizations and several properties concerning contra $g p^{*}$-continuous functions are obtained. Mathematics Subject Classification: 54 C 05, 54 C 08, 54 C10.
\end{abstract}

Keywords: $g p^{*}$ - open set, gp*-continuity, contra gp*-continuity.

\section{Introduction}

In 1970, Dontchev introduced the notions of contra continuous function. A new class of function called contra b-continuous function introduced by Nasef. In 2009, A.A.Omari and M.S.M.Noorani have studied further properties of contra b-continuous functions. In this paper, we introduce the concept of contra $\mathrm{gp}^{*}$-continuous function via the notion of gp*-open set and study some of the applications of this function. We also introduce and study two new spaces called gp*-Hausdorff spaces, gp*-normal spaces and obtain some new results.

Throughout this paper $(\mathrm{X}, \tau)$ and $(\mathrm{Y}, \sigma)$ represent the non-empty topological spaces on which no separation axioms are assumed, unless otherwise mentioned. Let $\mathrm{A} \subseteq \mathrm{X}$, the closure of $\mathrm{A}$ and interior of $\mathrm{A}$ will be denoted by cl (A) and int (A) respectively, union of all gp*-open sets X contained in A is called gp*-interior of $\mathrm{A}$ and it is denoted by $\mathrm{gp}^{*}$-int $(\mathrm{A})$, the intersection of all gp*-closed sets of $\mathrm{X}$ containing $\mathrm{A}$ is called gp*closure of $\mathrm{A}$ and it is denoted by gp*-cl(A).

\section{Preliminaries.}

Definition 2.1[8]: Let A subset A of a topological space (X, $\tau$ ), is called a pre-open set if $\mathrm{A} \subseteq \operatorname{Int}(\mathrm{cl}(\mathrm{A})$ ).

Definition 2.2 [16]: Let A subset A of a topological space (X, $\tau$ ), is called a generalized closed set (briefly gclosed) if cl (A) $\subseteq \mathrm{U}$ whenever $\mathrm{A} \subseteq \mathrm{U}$ and $\mathrm{U}$ is open in $\mathrm{X}$.

Definition 2.3 [10]: Let A subset A of a topological space (X, $\tau$ ), is called a generalized pre- closed set (briefly gp- closed) if pcl (A) $\subseteq \mathrm{U}$ whenever $\mathrm{A} \subseteq \mathrm{U}$ and $\mathrm{U}$ is open in $\mathrm{X}$.

Definition 2.4 [7]: Let A subset A of a topological space (X, $\tau$ ), is called a generalized pre-closed set (briefly pg-closed) if pcl(A) $\subseteq \mathrm{U}$ whenever $\mathrm{A} \subseteq \mathrm{U}$ and $\mathrm{U}$ is pre-open in $\mathrm{X}$.

Definition 2.5 [14]: Let A subset A of a topological space (X, $\tau$ ), is called a generalized pre- closed set (briefly $\mathrm{g}^{*}$ - closed) if cl (A) $\subseteq \mathrm{U}$ whenever $\mathrm{A} \subseteq \mathrm{U}$ and $\mathrm{U}$ is g-open in $\mathrm{X}$.

Definition 2.6 [18]: Let A subset A of a topological space (X, $\tau$ ), is called a generalized pre- closed set (briefly $\mathrm{g}^{*} \mathrm{p}$-closed) if pcl $(\mathrm{A}) \subseteq \mathrm{U}$ whenever $\mathrm{A} \subseteq \mathrm{U}$ and $\mathrm{U}$ is g-open in $\mathrm{X}$.

Definition 2.7 [15]: Let A subset A of a topological space (X, $\tau$ ), is called a generalized pre- closed set (briefly strongly g- closed) if cl (A) $\subseteq \mathrm{U}$ whenever $\mathrm{A} \subseteq \mathrm{U}$ and $\mathrm{U}$ is g-open in $\mathrm{X}$.

Definition 2.9 [17]: Let A subset A of a topological space (X, $\tau$ ), is called a generalized pre- closed set (briefly g\# closed) if cl(A) $\subseteq \mathrm{U}$ whenever $\mathrm{A} \subseteq \mathrm{U}$ and $\mathrm{U}$ is $\alpha$ g-open in $\mathrm{X}$.

Definition 2.10 [4]: A subset A of a topological space (X, $\tau$ ), is called gp ${ }^{*}$-closed set if cl (A) $\subseteq \mathrm{U}$ whenever $\mathrm{A} \subseteq \mathrm{U}$ and $\mathrm{U}$ is gp open in $\mathrm{X}$.

Definition 2.2. A function $\mathrm{f}:(\mathrm{X}, \tau) \rightarrow(\mathrm{Y}, \sigma)$ is called

(i) a contra continuous[1] if $\mathrm{f}^{1}(\mathrm{~V})$ is closed in $(\mathrm{X}, \tau)$ for every open set $\mathrm{V}$ of $(\mathrm{Y}, \sigma)$.

(ii) a contra $\mathrm{g}^{*}$-continuous $[14]$ if $\mathrm{f}^{1}(\mathrm{~V})$ is $\mathrm{g}^{*}$-closed in $(\mathrm{X}, \tau)$ for every open set $\mathrm{V}$ of $(\mathrm{Y}, \sigma)$.

(iii) a contra pg-continuous [7] if $\mathrm{f}^{-1}(\mathrm{~V})$ is pg-closed in $(\mathrm{X}, \tau)$ for every open set $\mathrm{V}$ of $(\mathrm{Y}, \sigma)$.

(iv) a contra $\mathrm{g}^{*} \mathrm{p}$-continuous $[18]$ if $\mathrm{f}^{1}(\mathrm{~V})$ is $\mathrm{g}^{*} \mathrm{p}$-closed in $(\mathrm{X}, \tau)$ for every open set $\mathrm{V}$ of $(\mathrm{Y}, \sigma)$.

(v) a contra strongly g-continuous $[15]$ if $\mathrm{f}^{1}(\mathrm{~V})$ is strongly g-closed in $(\mathrm{X}, \tau)$ for every open set $\mathrm{V}$ of $(\mathrm{Y}, \sigma)$.

(vi) a contra g\#-continuous [17] if $\mathrm{f}^{1}(\mathrm{~V})$ is $\mathrm{g \# -closed} \mathrm{in}(\mathrm{X}, \tau)$ for every open set $\mathrm{V}$ of $(\mathrm{Y}, \sigma)$. 


\section{Contra gp*Continuous Functions}

In this section, we introduce contra gp*-continuous functions and investigate some of their properties.

Definition 3.1. A function $\mathrm{f}:(\mathrm{X}, \tau) \rightarrow(\mathrm{Y}, \sigma)$ is called contra gp*-continuous if $\mathrm{f}^{1}(\mathrm{~V})$ is gp*-closed in $(\mathrm{X}, \tau)$ for every open set $\mathrm{V}$ in $(\mathrm{Y}, \sigma)$.

Example.3.2. Let $\mathrm{X}=\mathrm{Y}=\{\mathrm{a}, \mathrm{b}, \mathrm{c}\}$ with $\tau=\{\mathrm{X}, \varphi,\{\mathrm{a}\},\{\mathrm{b}\},\{\mathrm{a}, \mathrm{b}\}\}$ and $\sigma=\{\mathrm{Y}, \varphi,\{\mathrm{a}, \mathrm{b}\}\}$. Define a function $\mathrm{f}$ : $(\mathrm{X}, \tau) \rightarrow(\mathrm{Y}, \sigma)$ by $\mathrm{f}(\mathrm{a})=\mathrm{b}, \mathrm{f}(\mathrm{b})=\mathrm{c}, \mathrm{f}(\mathrm{c})=\mathrm{a}$. Clearly $\mathrm{f}$ is contra gp*-continuous.

Definition3.3. [11] Let A be a subset of a space (X, $\tau$ ).

(i) The set $\cap\{F \subset X: A \subset F, F$ is gp*-closed $\}$ is called the gp*-closure of $A$ and it is denoted by gp*-cl(A).

(ii) The set $\cup\{G \subset X: G \subset A, G$ is gp*-open $\}$ is called the gp*-interior of $A$ and it is denoted by gp*-int(A).

Lemma 3.4. For $\mathrm{x} \in \mathrm{X}, \mathrm{x} \in \mathrm{gp} \mathrm{p}^{*}$-cl (A) if and only if $\mathrm{U} \cap \mathrm{A} \neq \phi$ for every gp*-open set $\mathrm{U}$ containing $\mathrm{x}$.

\section{Proof.}

Necessary part: Suppose there exists a gp*-open set $U$ containing $x$ such that $U \cap A=\varphi$. Since $A \subset X-U$, gp*$\mathrm{cl}(\mathrm{A}) \subset \mathrm{X}-\mathrm{U}$. This implies $\mathrm{x} \notin \mathrm{gp} *$-cl(A). This is a contradiction.

Sufficiency part: Suppose that $\mathrm{x} \notin \mathrm{gp}{ }^{*}$-cl(A). Then $\exists \mathrm{a}$ gp*-closed subset $\mathrm{F}$ containing A such that $\mathrm{x} \notin \mathrm{F}$. Then $\mathrm{x} \in \mathrm{X}-\mathrm{F}$ is gp*-open, (X-F) $\cap \mathrm{A}=\varphi$. This is contradiction.

Lemma 3.5. The following properties hold for subsets $A, B$ of a space $X$ :

(i) $\mathrm{x} \in \operatorname{ker}(\mathrm{A})$ if and only if $\mathrm{A} \cap \mathrm{F} \neq \phi$ for any $\mathrm{F} \in(\mathrm{X}, \mathrm{x})$.

(ii) $\mathrm{A} \subset \operatorname{ker}(\mathrm{A})$ and $\mathrm{A}=\operatorname{ker}(\mathrm{A})$ if $\mathrm{A}$ is open in $\mathrm{X}$.

(iii) If $A \subset B$, then $\operatorname{ker}(A) \subset \operatorname{ker}(B)$.

Theorem 3.6. Let $\mathrm{f}:(\mathrm{X}, \tau) \rightarrow(\mathrm{Y}, \sigma)$ be a map. The following conditions are equivalent:

(i) $\mathrm{f}$ is contra gp*-continuous,

(ii) The inverse image of each closed in $(\mathrm{Y}, \sigma)$ is gp*-open in $(\mathrm{X}, \tau)$,

(iii) For each $\mathrm{x} \in \mathrm{X}$ and each $\mathrm{F} \in \mathrm{C}(\mathrm{Y}, \mathrm{f}(\mathrm{x}))$, there exists $\mathrm{U} \in \mathrm{gp}$ *- $\mathrm{O}(\mathrm{X})$, such that $\mathrm{f}(\mathrm{U}) \subset \mathrm{F}$,

(iv) $\mathrm{f}(\mathrm{gp} * \mathrm{-cl}(\mathrm{X})) \subset \operatorname{ker}(\mathrm{f}(\mathrm{A}))$, for every subset $\mathrm{A}$ of $\mathrm{X}$,

(v) $\mathrm{gp}^{*}\left(\mathrm{f}^{1}(\mathrm{~B})\right) \subset \mathrm{f}^{1}(\operatorname{ker}(\mathrm{B}))$, for every subset $\mathrm{B}$ of $\mathrm{Y}$.

Proof: (i) $\Leftrightarrow$ (ii) and (ii) $\Rightarrow$ (iii) are obvious.

(iii) $\Rightarrow$ (ii): Let $F$ be any closed set of $Y$ and $x \in f^{1}(F)$. Then $f(x) \in F$ and there exists $U_{x} \in g p^{*}-O(X, x)$ such that $\mathrm{f}\left(\mathrm{U}_{\mathrm{x}}\right) \subset \mathrm{F}$. Hence we obtain $\mathrm{f}^{1}(\mathrm{~F})=\cup\left\{\mathrm{U}_{\mathrm{x}} / \mathrm{x} \in \mathrm{f}^{1}(\mathrm{~F})\right\} \in \mathrm{gp}^{*}-\mathrm{O}(\mathrm{X}, \mathrm{x})$. Thus the inverse of each closed set in $(\mathrm{Y}, \sigma)$ is gp*-open in $(\mathrm{X}, \tau)$.

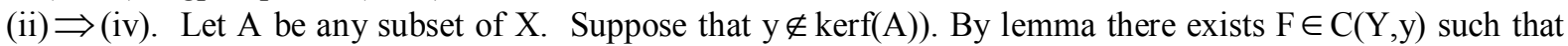
$\mathrm{f}(\mathrm{A}) \cap \mathrm{F}=\varphi$. Then, we have $\mathrm{A} \cap \mathrm{f}^{1}(\mathrm{~F})=\varphi$ and $\quad \mathrm{gp}^{*}-\mathrm{cl}(\mathrm{A}) \cap \mathrm{f}^{1}(\mathrm{~F})=\varphi$. Therefore, we obtain $\mathrm{f}(\mathrm{gp} *$-cl(A) $) \cap \mathrm{F}=\varphi$ and $\mathrm{y} \notin \mathrm{f}\left(\mathrm{gp} *\right.$-cl(A)). Hence we have $\mathrm{f}\left(\mathrm{gp}^{*}\right.$-cl $\left.(\mathrm{X})\right) \subset \operatorname{ker}(\mathrm{f}(\mathrm{A}))$.

(iv) $\Rightarrow(\mathrm{v})$ : Let $\mathrm{B}$ be any subset of $\mathrm{Y}$. By (iv) and Lemma, We have $\mathrm{f}\left(\mathrm{gp}^{*}\right.$-cl $\left.\left(\mathrm{f}^{1}(\mathrm{~B})\right)\right) \subset\left(\operatorname{ker}\left(\mathrm{f}\left(\mathrm{f}^{1}(\mathrm{~B})\right)\right)\right.$ $\subset \operatorname{ker}(\mathrm{B})$ and $\mathrm{gp}^{*}-\mathrm{cl}\left(\mathrm{f}^{1}(\mathrm{~B})\right) \subset \mathrm{f}^{1}(\operatorname{ker}(\mathrm{B}))$.

(v) $\Rightarrow$ (i): Let $V$ be any open set of $Y$. By lemma We have gp*-cl( $\left.f^{1}(V)\right) \subset \quad \mathrm{f}^{1}(\operatorname{ker}(\mathrm{V}))=\mathrm{f}^{1}(\mathrm{~V})$ and $g p^{*}-\operatorname{cl}\left(f^{1}(V)\right)=f^{1}(V)$. It follows that $f^{1}(V)$ is gp*-closed in $\mathrm{X}$. We have $\mathrm{f}$ is contra gp*-continuous.

Definition 3.7. A function $\mathrm{f}:(\mathrm{X}, \tau) \rightarrow(\mathrm{Y}, \sigma)$ is called gp*-continuous if the pre image of every open set of $\mathrm{Y}$ is gp*-open in $\mathrm{X}$.

Remark 3.8: The following two examples will show that the concept of gp*-continuity and contra gp*continuity are independent from each other.

Example 3.9. Let $\mathrm{X}=\mathrm{Y}=\{\mathrm{a}, \mathrm{b}, \mathrm{c}\}$ with $\tau=\{\mathrm{X}, \varphi,\{\mathrm{a}\},\{\mathrm{c}\},\{\mathrm{a}, \mathrm{c}\}\}$ and $\sigma=\{\mathrm{Y}, \varphi,\{\mathrm{b}, \mathrm{c}\}\}$. Define a function f: $(\mathrm{X}, \tau) \rightarrow(\mathrm{Y}, \sigma)$ by $\mathrm{f}(\mathrm{a})=\mathrm{a}, \mathrm{f}(\mathrm{b})=\mathrm{b}, \mathrm{f}(\mathrm{c})=\mathrm{c}$. Clearly $\mathrm{f}$ is contra gp*-continuous but $\mathrm{f}$ is not gp*-continuous. Because $\mathrm{f}^{1}(\{\mathrm{~b}, \mathrm{c}\})=\{\mathrm{b}, \mathrm{c}\}$ is not gp*-open in $(\mathrm{X}, \tau)$ where $\{\mathrm{b}, \mathrm{c}\}$ is open in $(\mathrm{Y}, \sigma)$. 
Example 3.10. Let $\mathrm{X}=\mathrm{Y}=\{\mathrm{a}, \mathrm{b}, \mathrm{c}\}$ with $\tau=\{\mathrm{X}, \varphi,\{\mathrm{a}\},\{\mathrm{a}, \mathrm{b}\}\}$ and $\sigma=\{\mathrm{Y}, \varphi,\{\mathrm{a}, \mathrm{c}\}\}$. Define a function $\mathrm{f}$ : $(\mathrm{X}, \tau) \rightarrow(\mathrm{Y}, \sigma)$ by $\mathrm{f}(\mathrm{a})=\mathrm{c}, \mathrm{f}(\mathrm{b})=\mathrm{a}, \mathrm{f}(\mathrm{c})=\mathrm{b}$. Clearly $\mathrm{f}$ is gp*-continuous but $\mathrm{f}$ is not contra gp*-continuous. Because $\mathrm{f}^{1}(\{\mathrm{a}, \mathrm{c}\})=\{\mathrm{a}, \mathrm{b}\}$ is not contra $\mathrm{gp}{ }^{*}$-closed $\operatorname{in}(\mathrm{X}, \tau)$ where $\{\mathrm{a}, \mathrm{c}\}$ is open in $(\mathrm{Y}, \sigma)$.

Theorem 3.11. If a function $\mathrm{f}:(\mathrm{X}, \tau) \rightarrow(\mathrm{Y}, \sigma)$ is contra gp*-continuous and $\quad(\mathrm{Y}, \sigma)$ is regular then $\mathrm{f}$ is gp*-continuous.

Proof: Let $\mathrm{x}$ be an arbitrary point of $(\mathrm{X}, \tau)$ and $\mathrm{V}$ be an open set of $(\mathrm{Y}, \sigma)$ containing $\mathrm{f}(\mathrm{x})$. Since $(\mathrm{Y}, \sigma)$ is regular, there exists an open set $\mathrm{W}$ of $(\mathrm{Y}, \sigma)$ containing $\mathrm{f}(\mathrm{x})$ such that $\mathrm{cl}(\mathrm{W}) \subset \mathrm{V}$. Since $\mathrm{f}$ is contra $\mathrm{gp}^{*}$ continuous, by theorem

There exists $\mathrm{U} \in \mathrm{gp}^{*}-\mathrm{O}(\mathrm{X}, \mathrm{x})$ such that $\mathrm{f}(\mathrm{U}) \subset \mathrm{cl}(\mathrm{W})$. Then $\mathrm{f}(\mathrm{U}) \subset \mathrm{cl}(\mathrm{W}) \subset \mathrm{V}$. Hence $\mathrm{f}$ is gp*-continuous.

Theorem 3.12. Every contra $g^{*}$-continuous function is contra gp*-continuous function.

Proof: Let $\mathrm{V}$ be an open set in $(\mathrm{Y}, \sigma)$. Since $\mathrm{f}$ is contra $\mathrm{g}^{*}$-continuous function, $\mathrm{f}^{1}(\mathrm{~V})$ is $\mathrm{g}^{*}$-closed in $(\mathrm{X}, \tau)$. Every $g^{*}$-closed set is gp*-closed. Hence $\mathrm{f}^{1}(\mathrm{~V})$ is $\mathrm{gp}^{*}$-closed $\operatorname{in}(\mathrm{X}, \tau)$. Thus $\mathrm{f}$ is contra gp*-continuous function.

Remark 3.13. The converse of theorem need not be true as shown in the following example.

Example 3.14. Let $\mathrm{X}=\mathrm{Y}=\{\mathrm{a}, \mathrm{b}, \mathrm{c}\}$ with $\tau=\{\mathrm{X}, \varphi,\{\mathrm{b}\},\{\mathrm{a}, \mathrm{b}\}\}$ and $\sigma=\{\mathrm{Y}, \varphi,\{\mathrm{b}, \mathrm{c}\}\}$. Define a function $\mathrm{f}$ : $(\mathrm{X}, \tau) \rightarrow(\mathrm{Y}, \sigma)$ by $\mathrm{f}(\mathrm{a})=\mathrm{b}, \mathrm{f}(\mathrm{b})=\mathrm{c}, \mathrm{f}(\mathrm{c})=\mathrm{a}$. Clearly $\mathrm{f}$ is contra gp*-continuous but $\mathrm{f}$ is not contra $\mathrm{g}^{*}$ continuous. Because $\mathrm{f}^{1}(\{\mathrm{~b}, \mathrm{c}\})=\{\mathrm{a}, \mathrm{b}\}$ is not $\mathrm{g}^{*}$-closed in $(\mathrm{X}, \tau)$ where $\{\mathrm{b}, \mathrm{c}\}$ is open in $(\mathrm{Y}, \sigma)$.

\section{Theorem 3.15.}

(i) Every contra pg-continuous function is contra gp*-continuous function.

(ii) Every contra $\mathrm{g}^{*} \mathrm{p}$-continuous function is contra gp*-continuous function.

(iii)Every contra strongly g-continuous function is contra gp*-continuous function.

(iv) Every contra g\#-continuous function is contra gp*-continuous function.

Remark 3.16. Converse of the above statements is not true as shown in the following example.

\section{Example 3.17.}

(i) Let $\mathrm{X}=\mathrm{Y}=\{\mathrm{a}, \mathrm{b}, \mathrm{c}\}$ with $\tau=\{\mathrm{X}, \varphi,\{\mathrm{a}\},\{\mathrm{b}\},\{\mathrm{a}, \mathrm{b}\},\{\mathrm{b}, \mathrm{c}\}\}$ and $\sigma=\{\mathrm{Y}, \varphi,\{\mathrm{b}, \mathrm{c}\}\}$. Define a function $\mathrm{f}$ : $(\mathrm{X}, \tau) \rightarrow(\mathrm{Y}, \sigma)$ by $\mathrm{f}(\mathrm{a})=\mathrm{c}, \mathrm{f}(\mathrm{b})=\mathrm{a}, \mathrm{f}(\mathrm{c})=\mathrm{b}$. Clearly $\mathrm{f}$ is contra gp*-continuous but $\mathrm{f}$ is not contra pgcontinuous. Because $\mathrm{f}^{1}(\{\mathrm{~b}, \mathrm{c}\})=\{\mathrm{a}, \mathrm{c}\}$ is not pg-closed in $(\mathrm{X}, \tau)$ where $\{\mathrm{b}, \mathrm{c}\}$ is open in $(\mathrm{Y}, \sigma)$.

(ii). Let $\mathrm{X}=\mathrm{Y}=\{\mathrm{a}, \mathrm{b}, \mathrm{c}\}$ with $\tau=\{\mathrm{X}, \varphi,\{\mathrm{a}\},\{\mathrm{c}\},\{\mathrm{a}, \mathrm{c}\},\{\mathrm{b}, \mathrm{c}\}\}$ and $\sigma=\{\mathrm{Y}, \varphi,\{\mathrm{a}, \mathrm{b}\}\}$. Define a function f: $(\mathrm{X}, \tau) \rightarrow(\mathrm{Y}, \sigma)$ by $\mathrm{f}(\mathrm{a})=\mathrm{b}, \mathrm{f}(\mathrm{b})=\mathrm{c}, \mathrm{f}(\mathrm{c})=\mathrm{a}$. Clearly $\mathrm{f}$ is contra gp*-continuous but $\mathrm{f}$ is not contra $\mathrm{g}^{*} \mathrm{p}$ continuous. Because $\mathrm{f}^{1}(\{\mathrm{a}, \mathrm{b}\})=\{\mathrm{a}, \mathrm{c}\}$ is not $\mathrm{g}^{*} \mathrm{p}$-closed in $(\mathrm{X}, \tau)$ where $\{\mathrm{a}, \mathrm{b}\}$ is open in $(\mathrm{Y}, \sigma)$.

(iii) Let $\mathrm{X}=\mathrm{Y}=\{\mathrm{a}, \mathrm{b}, \mathrm{c}\}$ with $\tau=\{\mathrm{X}, \varphi,\{\mathrm{a}, \mathrm{b}\}\}$ and $\sigma=\{\mathrm{Y}, \varphi,\{\mathrm{a}\}\}$. Define a function $\mathrm{f}$ : $(\mathrm{X}, \tau) \rightarrow(\mathrm{Y}, \sigma)$ by $\mathrm{f}(\mathrm{a})=\mathrm{c}, \mathrm{f}(\mathrm{b})=\mathrm{b}, \mathrm{f}(\mathrm{c})=\mathrm{a}$. Clearly $\mathrm{f}$ is contra $\quad \mathrm{gp} *$-continuous but $\mathrm{f}$ is not contra strongly g-continuous. Because $\mathrm{f}^{1}(\{\mathrm{a}\})=\{\mathrm{c}\}$ is not strongly $\mathrm{g}$-closed $\operatorname{in}(\mathrm{X}, \tau)$ where $\{\mathrm{a}\}$ is open in $(\mathrm{Y}, \sigma)$.

(iv) Let $\mathrm{X}=\mathrm{Y}=\{\mathrm{a}, \mathrm{b}, \mathrm{c}\}$ with $\tau=\{\mathrm{X}, \varphi,\{\mathrm{b}\}\}$ and $\sigma=\{\mathrm{Y}, \varphi,\{\mathrm{a}\}\}$. Define a function $\mathrm{f}:(\mathrm{X}, \tau) \rightarrow(\mathrm{Y}, \sigma)$ by $\mathrm{f}(\mathrm{a})$

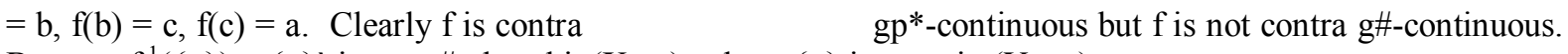
Because $\mathrm{f}^{1}(\{\mathrm{a}\})=\{c\}^{\prime}$ is not $\mathrm{g \# -closed}$ in $(\mathrm{X}, \tau)$ where $\{\mathrm{a}\}$ is open in $(\mathrm{Y}, \sigma)$.

Remark 3.18 The concept of contra gp*-continuous and contra gp-continuous are independent as shown in the following examples. 
Example 3.19. Let $\mathrm{X}=\mathrm{Y}=\{\mathrm{a}, \mathrm{b}, \mathrm{c}\}$ with $\tau=\{\mathrm{X}, \varphi,\{\mathrm{a}\},\{\mathrm{c}\},\{\mathrm{a}, \mathrm{c}\},\{\mathrm{b}, \mathrm{c}\}\}$ and $\sigma=\{\mathrm{Y}, \varphi,\{\mathrm{b}, \mathrm{c}\}\}$. Define a function $\mathrm{f}:(\mathrm{X}, \tau) \rightarrow(\mathrm{Y}, \sigma)$ by $\mathrm{f}(\mathrm{a})=\mathrm{b}, \mathrm{f}(\mathrm{b})=\mathrm{a}, \mathrm{f}(\mathrm{c})=\mathrm{c}$. Clearly $\mathrm{f}$ is contra gp*-continuous but $\mathrm{f}$ is not contra gp-continuous. Because $\mathrm{f}^{1}(\{\mathrm{~b}, \mathrm{c}\})=\{\mathrm{a}, \mathrm{c}\}$ is not gp-closed in $(\mathrm{X}, \tau)$ where $\{\mathrm{b}, \mathrm{c}\}$ is open in $(\mathrm{Y}, \sigma)$.

Example 3.20 Let $\mathrm{X}=\mathrm{Y}=\{\mathrm{a}, \mathrm{b}, \mathrm{c}\}$ with $\tau=\{\mathrm{X}, \varphi,\{\mathrm{c}\}\}$ and $\sigma=\{\mathrm{Y}, \varphi,\{\mathrm{a}, \mathrm{b}\}\}$. Define a function $\mathrm{f}:(\mathrm{X}, \tau) \rightarrow(\mathrm{Y}$, $\sigma)$ by $\mathrm{f}(\mathrm{a})=\mathrm{b}, \mathrm{f}(\mathrm{b})=\mathrm{c}, \mathrm{f}(\mathrm{c})=\mathrm{a}$. Clearly $\mathrm{f}$ is contra gp-continuous but $\mathrm{f}$ is not contra gp*-continuous. Because $\mathrm{f}^{1}(\{\mathrm{a}, \mathrm{b}\})=\{\mathrm{a}, \mathrm{c}\}$ is not $\mathrm{gp} *$-closed in $(\mathrm{X}, \tau)$ where $\{\mathrm{a}, \mathrm{b}\}$ is open in $(\mathrm{Y}, \sigma)$.

Definition 3.21. A space (X, $\tau$ ) is said to be (i) gp*-space if every gp*-open set of $X$ is open in $X$, (ii) locally $\mathrm{gp}^{*}$-indiscrete if every gp*-open set of $\mathrm{X}$ is closed in $\mathrm{X}$.

Theorem 3.22. If a function $f: X \rightarrow Y$ is contra $g p^{*}$-continuous and $X$ is gp*-space then $f$ is contra continuous.

Proof: Let $V \in O(Y)$. Then $f^{1}(V)$ is gp*-closed in $X$. Since $X$ is gp*-space, $f^{1}(V)$ is open in $X$. Hence $f$ is contra continuous.

Theorem 3.23. Let $\mathrm{X}$ be locally gp*-indiscrete. If $\mathrm{f}: \mathrm{X} \rightarrow \mathrm{Y}$ is contra gp*-continuous, then it is continuous.

Proof: Let $V \in O(Y)$. Then $f^{1}(V)$ is gp*-closed in $X$. Since $X$ is locally gp*-indiscrete space, $f^{1}(V)$ is open in $\mathrm{X}$. Hence $\mathrm{f}$ is continuous.

Definition 3.24. A function $f: X \rightarrow Y$, the subset $\{(x, f(x)): x \in X\} \subset X \times Y$ is called the graph of $f$ and is denoted by $\mathrm{G}_{\mathrm{f}}$.

Definition 3.25. The graph $G_{f}$ of a function $f: X \rightarrow Y$ is said to be contra gp*-closed if for each $(x, y) \in(X \times$ $\mathrm{Y})-\mathrm{G}_{\mathrm{f}}$ there exists $\mathrm{U} \in \mathrm{gp}^{*}-\mathrm{O}(\mathrm{X}, \mathrm{y})$ and $\mathrm{V} \in \mathrm{C}(\mathrm{Y}, \mathrm{y})$ such that $(\mathrm{U} \times \mathrm{V}) \cap \mathrm{G}_{\mathrm{f}}$.

Theorem 3.26. If a function $f: X \rightarrow Y$ is contra $g p^{*}$-continuous and $Y$ is Urysohn, then $G_{f}$ is contra gp*closed in the product space $\mathrm{X} \times \mathrm{Y}$.

Proof: Let $(x, y) \in(X \times Y)-G_{f}$. Then $y \neq f(x)$ and there exist open sets $H_{1}, H_{2}$ such that $f(x) \in H_{1}, y \in H_{2}$ and $\mathrm{cl}\left(\mathrm{H}_{1}\right) \cap \mathrm{cl}\left(\mathrm{H}_{2}\right)=\varphi$. From hypothesis, there exists $\mathrm{V} \in \mathrm{gp}{ }^{*}-\mathrm{O}(\mathrm{X}, \mathrm{x})$ such that $\mathrm{f}(\mathrm{V}) \subset \mathrm{cl}\left(\mathrm{H}_{1}\right)$. Therefore, we have $\mathrm{f}(\mathrm{V}) \cap \mathrm{cl}\left(\mathrm{H}_{2}\right)=\varphi$. This shows that $\mathrm{G}_{\mathrm{f}}$ is contra gp*-closed in the product space $\mathrm{X} \times \mathrm{Y}$.

Theorem 3.27. If $\mathrm{f}: \mathrm{X} \rightarrow \mathrm{Y}$ is gp*-continuous and $\mathrm{Y}$ is $\mathrm{T}_{1}$, then $\mathrm{Gf}$ is contra gp*-closed in $\mathrm{X} \times \mathrm{Y}$.

Proof. Let $(x, y) \in(X \times Y)-G_{f}$. Then $y \neq f(x)$ and there exist open set $V$ of $Y$ such that $f(x) \in V$ and $y \notin V$. Since $\mathrm{f}$ is gp*-continuous, there exists $\mathrm{U} \in\left(\mathrm{gp} \mathrm{p}^{*}-\mathrm{O}(\mathrm{X}, \mathrm{x})\right.$ such that $\mathrm{f}(\mathrm{U}) \subset \mathrm{V}$. Therefore, we have $\mathrm{f}(\mathrm{U}) \cap(\mathrm{Y}-\mathrm{V})$ $=\varphi$ and $(\mathrm{Y}-\mathrm{V}) \in\left(\mathrm{gp}^{*}-\mathrm{C}(\mathrm{Y}, \mathrm{y})\right.$. This shows that $\mathrm{G}_{\mathrm{f}}$ is contra gp*-closed in $\mathrm{X} \times \mathrm{Y}$.

Theorem 3.28. Let $\mathrm{f}: \mathrm{X} \rightarrow \mathrm{Y}$ be a function and $\mathrm{g}: \mathrm{X} \rightarrow \mathrm{X} \times \mathrm{Y}$, the graph function of $\mathrm{f}$, defined by $\mathrm{g}(\mathrm{x})=(\mathrm{x}$, $f(x))$ for every $x \in X$. If $g$ is contra $g p^{*}$-continuous, then $f$ is contra gp*-continuous.

Proof. Let $\mathrm{U}$ be an open set in $\mathrm{Y}$, then $\mathrm{X} \times \mathrm{U}$ is an open set in $\mathrm{X} \times \mathrm{Y}$. Since $\mathrm{g}$ is contra gp*-continuous. It follows that $\mathrm{f}^{1}(\mathrm{U})=\mathrm{g}^{-1}(\mathrm{X} \times \mathrm{U})$ is an $g p^{*}$-closed in $\mathrm{X}$. Hence $\mathrm{f}$ is $\mathrm{gp}{ }^{*}$-continuous.

Theorem 3.29. If $f: X \rightarrow Y$ is a contra gp*-continuous function and $g: Y \rightarrow Z$ is a continuous function, then $\mathrm{g} \circ \mathrm{f}: \mathrm{X} \rightarrow \mathrm{Z}$ is contra gp*-continuous.

Proof: Let $V \in O(Y)$. Then $g^{-1}(V)$ is open in $Y$. Since $f$ is contra gp*-continuous, $f^{-1}\left(g^{-1}(V)\right)=(g \circ f)^{-1}(V)$ is $\mathrm{gp}^{*}$-closed in $\mathrm{X}$. Therefore, $\mathrm{g} \circ \mathrm{f:} \mathrm{X} \rightarrow \mathrm{Z}$ is contra gp*-continuous.

Theorem 3.30. Let $\mathrm{p}: \mathrm{X} \times \mathrm{Y} \rightarrow \mathrm{Y}$ be a projection. If $\mathrm{A}$ is $g p^{*}$-closed subset $\mathrm{pf} X$, then $\mathrm{p}^{-1}(\mathrm{~A})=\mathrm{A} \times \mathrm{Y}$ is gp*closed subset of $\mathrm{X} \times \mathrm{Y}$. 
Proof: Let $A \times Y \subset U$ and $U$ be a regular open set of $X \times Y$. Then $U=X \times Y$ for some regular open set of $X$. Since A is gp*-closed in $X, b c l(A)$ and so bcl(A) $\times Y \subset V \times Y=U$. Therefore $b c l(A \times Y) \subset U$. Hence $A \times Y$ is gp*-closed sub set of $\mathrm{X} \times \mathrm{Y}$.

\section{Applications.}

Definition 4.1. A topological space $(\mathrm{X}, \tau)$ is said to be gp*-Hausdorff space if for each pair of distinct points $\mathrm{x}$ and $\mathrm{y}$ in $\mathrm{X}$ there exists $\mathrm{U} \in \mathrm{gp}{ }^{*}-\mathrm{O}(\mathrm{X}, \mathrm{x})$ and $\mathrm{V} \in \mathrm{gp}{ }^{*}-\mathrm{O}(\mathrm{X}, \mathrm{y})$ such that $\mathrm{U} \cap \mathrm{V}=\varphi$

Example 4.2. Let $\mathrm{X}=\{\mathrm{a}, \mathrm{b}, \mathrm{c}\}$ with $\tau=\{\mathrm{X}, \varphi,\{\mathrm{a}\},\{\mathrm{b}\},\{\mathrm{c}\},\{\mathrm{a}, \mathrm{b}\},\{\mathrm{b}, \mathrm{c}\},\{\mathrm{a}, \mathrm{c}\}\}$. Let $\mathrm{x}$ and $\mathrm{y}$ be two distinct points of $\mathrm{X}$, there exists an gp*-open neighbourhood of $\mathrm{x}$ and $\mathrm{y}$ respectively such that $\{\mathrm{x}\} \cap\{\mathrm{y}\}=\varphi$. Hence $(\mathrm{X}, \tau)$ is gp*-Hausdorff space.

Theorem 4.3. If $X$ is a topological space and for each pair of distinct points $x_{1}$ and $x_{2}$ in $X$, there exists a function $\mathrm{f}$ of $\mathrm{X}$ into Uryshon topological space $\mathrm{Y}$ such that $\mathrm{f}\left(\mathrm{x}_{1}\right) \neq \mathrm{f}\left(\mathrm{x}_{2}\right)$ and $\mathrm{f}$ is contra gp*-continuous at $\mathrm{x}_{1}$ and $\mathrm{x}_{2}$, then $\mathrm{X}$ is gp*-Hausdorff space.

Proof: Let $x_{1}$ and $x_{2}$ be any distinct points in $X$. By hypothesis, there is a Uryshon space $Y$ and a function $f$ : $\mathrm{X} \rightarrow \mathrm{Y}$ such that $\mathrm{f}\left(\mathrm{x}_{1}\right) \neq \mathrm{f}\left(\mathrm{x}_{2}\right)$ and $\mathrm{f}$ is contra gp*-continuous at $\mathrm{x}_{1}$ and $\mathrm{x}_{2}$. Let $\mathrm{y}_{\mathrm{i}}=\mathrm{f}\left(\mathrm{x}_{\mathrm{i}}\right)$ for $\mathrm{i}=1,2$ then $\mathrm{y}_{1} \neq \mathrm{y}_{2}$. Since $\mathrm{Y}$ is Uryshon, there exists open sets $\mathrm{U}_{\mathrm{y} 1}$ and $\mathrm{U}_{\mathrm{y} 2}$ containing $\mathrm{y}_{1}$ and $\mathrm{y}_{2}$ respectively in $\mathrm{Y}$ such that $\operatorname{cl}\left(\mathrm{U}_{\mathrm{y} 1}\right) \cap \operatorname{cl}\left(\mathrm{U}_{\mathrm{y} 2}\right)=\varphi$. Since $\mathrm{f}$ is contra gp*-continuous at $\mathrm{x}_{1}$ and $\mathrm{x}_{2}$, there exists and gp*-open sets $\mathrm{V}_{\mathrm{x} 1}$ and $\mathrm{V}_{\mathrm{x} 2}$ containing $\mathrm{x}_{1}$ and $\mathrm{x}_{2}$ respectively in $\mathrm{X}$ such that $\mathrm{f}\left(\mathrm{V}_{\mathrm{xi}}\right) \subset \mathrm{cl}\left(\mathrm{U}_{\mathrm{yi}}\right)$ for $\mathrm{i}=1,2$. Hence we have $\left(\mathrm{V}_{\mathrm{x} 1}\right) \cap\left(\mathrm{V}_{\mathrm{x} 2}\right)=\varphi$. Therefore $\mathrm{X}$ is gp*-Hausdorff space.

Corollary 4.4. If $\mathrm{f}$ is contra gp*-continuous injection of a topological space $\mathrm{X}$ into a Uryshon space $\mathrm{Y}$ then $\mathrm{Y}$ is gp*-Hausdorff.

Proof: Let $\mathrm{x}_{1}$ and $\mathrm{x}_{2}$ be any distinct points in $\mathrm{X}$. By hypothesis, $\mathrm{f}$ is contra gp*-continuous function of $\mathrm{X}$ into a Uryshon space $Y$ such that $\mathrm{f}\left(\mathrm{x}_{1}\right) \neq \mathrm{f}\left(\mathrm{x}_{2}\right)$, because $\mathrm{f}$ is injective. Hence by theorem, $\mathrm{X}$ is gp*-Hausdorff.

Definition 4.5. A topological space $(\mathrm{X}, \tau)$ is said to be gp*-normal if each pair of non-empty disjoint closed sets in $(\mathrm{X}, \tau)$ can be separated by disjoint gp*-open sets in $(\mathrm{X}, \tau)$.

Definition 4.6. A topological space $(X, \tau)$ is said to be ultra normal if each pair of non-empty disjoint closed sets in $(\mathrm{X}, \tau)$ can be separated by disjoint clopen sets in $(\mathrm{X}, \tau)$.

Theorem 4.7. If $\mathrm{f}: \mathrm{X} \rightarrow \mathrm{Y}$ is a contra $\mathrm{gp}$ *-continuous function, closed, injection and $\mathrm{Y}$ is Ultra normal, then $\mathrm{X}$ is gp*-normal.

Proof: Let $U$ and $V$ be disjoint closed subsets of $X$. Since $f$ is closed and injective, $f(U)$ and $f(V)$ are disjoint subsets of $Y$. Since $Y$ is ultra normal, there exists disjoint closed sets $A$ and $B$ such that $f(U) \subset A$ and $f(V) \subset B$. Hence $U \subset f^{1}(A)$ and $V \subset f^{1}(B)$. Since $f$ is contra $g p^{*}$-continuous and injective, $f^{-1}(A)$ and $f^{1}(B)$ are disjoint $\mathrm{gp}^{*}$-open sets in $\mathrm{X}$. Hence $\mathrm{X}$ is gp*-normal.

Definition4.8. [13] A topological space $X$ is said to be gp*-connected if $X$ is not the union of two disjoint nonempty gp*-open sets of X.

Theorem 4.9. A contra gp*-continuous image of a gp*-connected space is connected.

Proof: Let $\mathrm{f}: \mathrm{X} \rightarrow \mathrm{Y}$ is a contra gp*-continuous function of $\mathrm{gp}^{*}$-connected space $\mathrm{X}$ onto a topological space $\mathrm{Y}$. If possible, let $\mathrm{Y}$ be disconnected. Let $\mathrm{A}$ and $\mathrm{B}$ form disconnectedness of $\mathrm{Y}$. Then $\mathrm{A}$ and $\mathrm{B}$ are clopen and $\mathrm{Y}=$ $A \cup B$ where $A \cap B=\varphi$. Since $f$ is contra gp*-continuous, $X=f^{1}(Y)=f^{1}(A \cup B)=f^{1}(A) \cup f^{1}(B)$ where $f$ ${ }^{1}(\mathrm{~A})$ and $\mathrm{f}^{1}(\mathrm{~B})$ are non-empty gp*-open sets in $\mathrm{X}$. Also $\mathrm{f}^{1}(\mathrm{~A}) \cap \mathrm{f}^{1}(\mathrm{~B})=\varphi$. Hence $\mathrm{X}$ is non-gp*-connected which a contradiction is. Therefore $\mathrm{Y}$ is connected.

Theorem 4.10. Let $X$ be $g p^{*}$-connected and $Y$ be $T_{1}$. If $f: X \rightarrow Y$ is a contra gp*-continuous, then $f$ is constant.

Proof: Since $Y$ is $T_{1}$ space $v=\left\{f^{1}(y): y \in Y\right\}$ is a disjoint gp*-open partition of $X$. If $|v| \geq 2$, then $X$ is the union of two non empty gp*-open sets. Since $\mathrm{X}$ is gp*-connected, $|\mathrm{v}|=1$. Hence $\mathrm{f}$ is constant. 
Theorem 4.11. If $\mathrm{f}: \mathrm{X} \rightarrow \mathrm{Y}$ is a contra gp*-continuous function from gp*-connected space $\mathrm{X}$ onto space $\mathrm{Y}$, then $\mathrm{Y}$ is not a discrete space.

Proof: Suppose that $Y$ is discrete. Let A be a proper non-empty open and closed subset of $Y$. Then $\mathrm{f}^{1}(\mathrm{~A})$ is a proper non-empty gp*-clopen subset of $\mathrm{X}$, which is a contradiction to the fact $\mathrm{X}$ is gp*-connected.

\section{References}

[1]. Dontchev J., Contra continuous functions and strongly S-closed spaces. Int Math Sci, 19 (1996) 303-310.

[2]. Dontchev J. and Noiri T., Contra semi continuous functions. Math Pannonica, 10 (1999) 159-168.

[3]. Jafari.S and T. Noiri, On contra-precontinuous functions, Bull. Malays. Math. Sci. Soc. (2) 25(2) (2002), 115-128.

[4]. Jayakymar.P, Mariappa.K and S.Sekar, On generalized gp*- closed set in Topological Spaces, Int. Journal of Math. Analysis, Vol. 7,2013, no. $33,1635-1645$.

[5]. Levine.N, Generalized closed sets in topology, Tend Circ., Mat. Palermo (2) 19 (1970), 89-96.

[6]. Maki.H, R.Devi and K.Balachandran, Associated topologies of generalized $\alpha$-closed sets and $\alpha$-generalized closed sets Mem. Fac. Sci. Kochi. Univ. Ser. A.Math. 15 (1994), 51- 63.

[7]. Maki.H, R.J.Umehara and T.Noiri, Every topological space is pre-T $1 / 2$, Mem. Fac. Sci. Kochi. Univ. Ser. A. Math. 17(1996), 3342.

[8]. Mashor Abd.El-Monsef.M.E and Ei-Deeb.S.N., On Pre continous and weak pre-continous mapping, Proc.Math.,Phys.Soc.Egypt, 53 (1982), 47-53.

[9]. Metin Akdag and Alkan Ozkan, Some properties of Contra gb-continuous functions, Journal of New results in Science 1 (2012) 4049.

[10]. Njastad.O, On some classes of nearly open sets, Pacific J Math., 15(1965),961-970 .

[11]. Sekar.S and Jayakumar.P, On gp*- continuous map in Topological Spaces-Communicated.

[12]. Sekar.S and Jayakumar.P, On gp*-interior and gp*-closure in Topological Spaces -Communicated.

[13]. Sekar.S and Jayakumar.P On gp*- connectedness and gp*-compactness in Topological spaces-Communicated.

[14]. Sekar.S and Jayakumar.P, On Generalized gp*- Closed Map in Topological Spaces, Applied Mathematical Sciences, Vol. 8, 2014, no. $9,415-422$

[15]. Somasundaram.S., Murugalingam.M. and Palaniammal.S. 2005. A generalized Star Sets.Bulletin of Pure and Applied Sciences.Vol.24E (No.2) : 233-238.

[16]. Sundaram.P. and A.Pushpaplatha.2001.Strongly generalized closed sets in topological spaces. Far East J.Math.Sci., 3(4): 563 -575.

[17]. Veerakumar. M.K.R.S., Between closed sets and g-closed sets. Mem. Fac. Sci, Kochi Univ.Ser.A.Math, 1721 (2000),1-19.

[18]. Veerakumar.M.K.R.S., g\#-closed sets in topological spaces, Kochi J.Math., 24(2003), 1-13

[19]. Veera kumar.M.K.R.S., g*- pre-closed sets, Acta Ciencia India, Vol XXVIII M, No 1, (2002), 51 - 60 